\title{
Predation of the introduced cladoceran Cercopagis pengoi on the native copepod Eurytemora affinis in the northern Baltic Sea
}

\author{
Maiju Lehtiniemi ${ }^{1, *}$, Elena Gorokhova ${ }^{2}$ \\ ${ }^{1}$ Finnish Institute of Marine Research, PO Box 2, 00561 Helsinki, Finland \\ ${ }^{2}$ Department of Systems Ecology, Stockholm University, 10691 Stockholm, Sweden
}

\begin{abstract}
We studied the potential of an introduced species, the predatory cladoceran Cercopagis pengoi, to influence native zooplankton populations in the Baltic Sea. Feeding rates (FRs) of different instars of $C$. pengoi on Eurytemora affinis, a dominant copepod species, were determined experimentally. The FRs of $C$. pengoi varied from 0.7 to 4.8 prey predator ${ }^{-1} \mathrm{~d}^{-1}$ and were significantly higher in older instars. Based on the experimental results and long-term zooplankton abundance data from the Gulf of Finland, we estimated the in situ predation rates. Our results imply that at maximum abundance, the C. pengoi population feeding in dense prey patches could consume as many as $10^{5} \mathrm{E}$. affinis $\mathrm{m}^{-3} \mathrm{~d}^{-1}$. This could explain the observed drastic decrease in copepod abundances in the eastern Gulf of Finland, the region with the highest C. pengoi abundance after the expansion of this species. Such a decline may strengthen food competition between other zooplanktivores, i.e. planktivorous fish and mysids, feeding on the same copepod prey in regions where C. pengoi may reach high abundances. In the Gulf of Finland, especially in the eastern parts, a collapse of E. affinis, a key species in the pelagic system, would cause major changes in virtually all trophic levels, because the food web structure is simple with only a few species of zooplankton, planktivores, and piscivores.
\end{abstract}

KEY WORDS: Introduced species $\cdot$ Predation $\cdot$ Food web dynamics $\cdot$ Cercopagis pengoi $\cdot$ Eurytemora affinis

Resale or republication not permitted without written consent of the publisher

\section{INTRODUCTION}

The pelagic food web structure is rather simple in the Baltic Sea and resembles that of the Laurentian Great Lakes of North America with only a few piscivores and planktivores. Baltic herring Clupea harengus membras L. and sprat Sprattus sprattus L. form a major part of the planktivorous fish populations, and mysid shrimps (Mysis mixta Lilljeborg, M. relicta Lovén, and M. salemaai Audzijonyte and Väinölä) are the dominating zooplanktivorous invertebrates (Viherluoto et al. 2000, Peltonen et al. 2004). Recently, however, the food web has experienced a major change. The predatory cladoceran Cercopagis pengoi (Ostroumov) invaded the Baltic Sea in 1992 (Ojaveer \& Lumberg 1995) and has established permanent populations throughout the Baltic (Gorokhova et al. 2000). To predict the potential predatory impact of the invader, one must know the actual predation rates on different prey organisms.

Currently, Cercopagis pengoi is recognized as a prey for planktivorous fish (e.g. Peltonen et al. 2004) and mysids (Gorokhova \& Lehtiniemi 2007). However, C. pengoi is also a zooplanktivore (Laxson et al. 2003, Lehtiniemi \& Lindén 2006) that may compete for herbivorous zooplankton with pelagic fish and mysids (Vanderploeg et al. 2002). To quantify this competition, feeding preferences and consumption rates of C. pengoi must be evaluated. However, apart from a few published experimental studies (Laxson et al. 2003, Lehtiniemi \& Lindén 2006, Simm et al. 2006), C. pengoi food preferences have been inferred only indirectly from 
alterations in demographic structure of zooplankton communities (Benoît et al. 2002, Ojaveer et al. 2004, Litvinchuk \& Telesh 2006) or using stable isotope analysis (Gorokhova et al. 2005). These studies suggest that C. pengoi feeds on small zooplankton (Laxson et al. 2003, Lehtiniemi \& Lindén 2006, Simm et al. 2006) and may therefore have negative effects on these populations by direct predation (Benoît et al. 2002, Ojaveer et al. 2004, Witt et al. 2005). Accurate estimates of the predation rates are lacking, hampering the evaluation of the impact of this cladoceran on prey communities.

The aim of this study was to investigate if and how Cercopagis pengoi may affect the population size of the calanoid copepod Eurytemora affinis Poppe through predation. We chose this copepod species because (1) it is one of the few dominant mesozooplankton species in the northern Baltic during the growing season (Viitasalo 1992), (2) it is a preferred prey for the dominant zooplanktivores, i.e. herring, sprat, and mysids (Flinkman et al. 1998, Viherluoto \& Viitasalo 2001, Peltonen et al. 2004), and (3) it has been suggested that its seasonal population development is influenced by $C$. pengoi predation (Ojaveer et al. 2004). To assay feeding rates (FRs) of C. pengoi on E. affinis, several feeding experiments were conducted to test for differences in consumption rates between: (1) smaller and larger C. pengoi preying on small and large copepods, (2) parthenogenic and gametogenic females of C. pengoi, and (3) C. pengoi exposed to different prey densities. Further, the consumption rates observed in these experiments were combined with the copepod abundances obtained from monitoring data over the years before (1992 to 1996) and after (1997 to 2004) the expansion of $C$. pengoi in the Gulf of Finland to calculate potential in situ predation rates on E. affinis. Finally, these estimates were related to the observed changes in E. affinis abundances to evaluate a potential impact of the invader.

\section{MATERIALS AND METHODS}

Collection and maintenance of experimental animals. The experimental animals were collected and the feeding experiments were conducted on board RV 'Aranda' (Finnish Institute of Marine Research, FIMR) in August 2005 in the Gulf of Finland, in the northern Baltic Sea. Cercopagis pengoi were collected from $50 \mathrm{~m}$ to the surface, using a
WP-2 closing plankton net (mesh size $500 \mu \mathrm{m}$ ) equipped with a cod end. Samples were kept in a temperature-controlled room $\left(15^{\circ} \mathrm{C}\right.$, approximating the temperature in the lower part of the mixing layer) with aeration. C. pengoi individuals were carefully picked under a dissecting microscope with forceps and pipettes from large aggregations formed during sampling. Only individuals with undamaged caudal appendages were selected, transferred individually to $0.2 \mu \mathrm{m}$-filtered seawater in $0.1 \mathrm{l}$ vials, and acclimated for at least $12 \mathrm{~h}$ without food before the experiments. Because the post-handling mortality and injury levels of $C$. pengoi are usually high, their condition was checked again after the acclimation period, and only actively swimming animals in visibly good condition were used in the experiments.

Zooplankton were collected by vertical hauls from $20 \mathrm{~m}$ to the surface with a WP-2 closing plankton net (mesh size $100 \mu \mathrm{m}$ ) with a cod end and kept at the same conditions as Cercopagis pengoi. Eurytemora affinis individuals were picked with a pipette under a dissecting microscope and kept in groups of 10 to 20 individuals in $0.2 \mu \mathrm{m}$-filtered seawater in $0.1 \mathrm{l}$ vials.

Experimental procedures. We conducted 7 feeding experiments using Cercopagis pengoi (instars II and III, of which both parthenogenic [PF] and gametogenic females [GF] were tested) as predators and copepodites (CI-III) and adults (CV-VI, males and females without egg sacks) of Eurytemora affinis as prey. We also measured the FR of C. pengoi at different prey (CI-III copepodites) densities (Table 1). PF and GF were tested separately because the stage of the reproductive cycle affects the energy budget and thus feeding in other

Table 1. Experimental details and sampling locations. Feeding experiments tested several combinations of predator and prey, and prey densities with Cercopagis pengoi (instars II and III: PF, parthenogenic females; GF, gametogenic females) as predators, and copepodites (CI-III, size: $0.43 \pm 0.02 \mathrm{~mm}$ ) and adults (CV-VI, size: $0.66 \pm 0.01 \mathrm{~mm})$ of Eurytemora affinis as prey. Number of replicates (n) does not include those where $C$. pengoi died or gave birth during the experiments (see text for further explanations). Pred.: predator; $\mathrm{BL}$ : body length (mean $\pm \mathrm{SE}$ ); Expts small, large: experiments with small and large prey, respectively

\begin{tabular}{|c|c|c|c|c|c|c|}
\hline Location & $\begin{array}{c}\text { Bottom } \\
\text { depth (m) }\end{array}$ & $\begin{array}{l}\text { Pred. stage } \\
\quad \text { (instar) }\end{array}$ & $\begin{array}{l}\text { Pred. BL } \\
\quad(\mathrm{mm})\end{array}$ & $\begin{array}{c}\text { Expts } \\
\text { small } \\
\text { (n) }\end{array}$ & $\begin{array}{c}\text { Expts } \\
\text { large } \\
\text { (n) }\end{array}$ & $\begin{array}{c}\text { Prey } \\
\text { density } \\
\text { (ind. } 1^{-1} \text { ) }\end{array}$ \\
\hline $\begin{array}{l}59^{\circ} 50.31^{\prime} \mathrm{N}, \\
25^{\circ} 51.41^{\prime} \mathrm{E}\end{array}$ & 84 & II & $1.43 \pm 0.1$ & 5 & 4 & 100 \\
\hline $\begin{array}{l}59^{\circ} 50.31^{\prime} \mathrm{N}, \\
25^{\circ} 51.41^{\prime} \mathrm{E}\end{array}$ & 84 & III PF & $2.1 \pm 0.1$ & 4 & 5 & 100 \\
\hline $\begin{array}{l}59^{\circ} 35.51^{\prime} \mathrm{N}, \\
24^{\circ} 20.81^{\prime} \mathrm{E}\end{array}$ & 85 & II & $1.43 \pm 0.1$ & 5 & - & 200 \\
\hline $\begin{array}{l}59^{\circ} 35.51^{\prime} \mathrm{N}, \\
24^{\circ} 20.81^{\prime} \mathrm{E}\end{array}$ & 85 & III PF & $2.1 \pm 0.1$ & 4 & - & 200 \\
\hline $\begin{array}{l}59^{\circ} 50.31^{\prime} \mathrm{N}, \\
25^{\circ} 51.41^{\prime} \mathrm{E}\end{array}$ & 84 & III GF & $2.08 \pm 0.1$ & 6 & - & 100 \\
\hline
\end{tabular}


crustaceans (Gorokhova \& Hansson 2000). All experiments were conducted in $0.1 \mathrm{l}$ vials in $0.2 \mu \mathrm{m}$-filtered seawater, in constant illumination at $15^{\circ} \mathrm{C}$, and lasted ca. $18 \mathrm{~h}$ due to the cruise schedule. The vials were not mixed during the incubations to prevent disturbing sensitive C. pengoi; the prey distribution in the vials was not likely to be affected by settling phytoplankton as there were no phytoplankton in the media. Experiments were started by adding a known number (10 or 20) of E. affinis to a single C. pengoi individual in the vial. When ending the experiment, the condition of $C$. pengoi was checked, and the vial contents were poured on a $20 \mu \mathrm{m}$ plankton net. The vials and the net were carefully rinsed several times to recover all prey items. Replicates in which C. pengoi died (8\%) or gave birth during the incubations (3\%) were excluded from the analysis. In addition, there were control incubations with the same number of prey organisms but without C. pengoi to correct for prey recovery (recovery rate 95 to $100 \%$ ). Experiments and controls were replicated 4 to 6 times. Recovered prey were preserved in acidic Lugol's solution and counted. Body length (BL) of every $C$. pengoi (from the top of the head to the base of the caudal claws; Table 1) and a subsample of $70 \mathrm{E}$. affinis individuals (prosome length, PL) was measured under a dissecting microscope. Experiments and controls were replicated 4 to 6 times. FR was calculated as the difference between the average number of prey recovered in the controls and final numbers of prey and scaled to $24 \mathrm{~h}$.

Estimating in situ predation rates. To estimate the potential effect that Cercopagis pengoi may have on Eurytemora affinis populations, we used monitoring data on $C$. pengoi and E. affinis abundances in the Gulf of Finland from 1992 to 2004 from the FIMR database. The zooplankton was collected in August and analyzed according to the standard protocol of the Baltic Monitoring Programme from 6 sampling stations and 2 depth layers (above and below the thermocline). To evaluate habitat effect, we grouped data by habitat (western part of the Gulf of Finland, central part, and eastern part; 2 stations per group), and compared abundance of $E$. affinis before (1992 to 1996) and after (1997 to 2004) the invasion of $C$. pengoi into these parts of the Gulf of Finland, both above and below the thermocline. To assess potential predation pressure on E. affinis by C. pengoi, abundances of E. affinis were pooled for early copepodites (CI-III) and older copepodites + adults (CIV-VI). The in situ population consumption rate of $C$. pengoi was then calculated based on our experimental results and natural abundances of $C$. pengoi and E. affinis. In these calculations, individual consumption rates of $C$. pengoi on copepodites CI-III and CIV-VI were assumed to be equal to those observed in our experiments for copepodites CI-III and adults CV-VI, respectively. Calculations were performed accounting for vertical heterogeneity of the copepod distribution and assuming that $\sim 80 \%$ of the E. affinis population was found near the thermocline in thin, $1 \mathrm{~m}$ layers as observed in summer in the northern Baltic proper (Nikolaev 1960, Gorokhova 1999).

Statistical tests. The differences between FRs of different developmental stages for both the predator and the prey were tested with 1-way analysis of variance (ANOVA) followed by Tukey's multiple comparisons tests. The data were $\log _{10}(x+1)$ transformed to fulfill assumptions for data continuity, normality, and homoscedasticity. Mann-Whitney $U$-test was used to test the differences between the abundance of Eurytemora affinis before and after Cercopagis pengoi invasion. Unless specified otherwise, results are presented as means with SEs; in all cases, significance was accepted when $\mathrm{p}<0.05$. All tests were performed with the statistical software STATISTICA 6.0 for Windows.

\section{RESULTS}

Both copepodites and adults of Eurytemora affinis were eaten by all tested ontogenetic stages and sexes of Cercopagis pengoi (Fig. 1). There were significant differences in the FRs between different instars of C. pengoi (ANOVA: $F_{2,20}=4.45, \mathrm{p}=0.025$ ), with $\mathrm{PF}$ Instar III eating significantly more copepods than Instar II individuals (Tukey's HSD test: $p=0.036$ ). There were no significant differences between the feeding rates of PF and GF, Instar III (Tukey's HSD test:

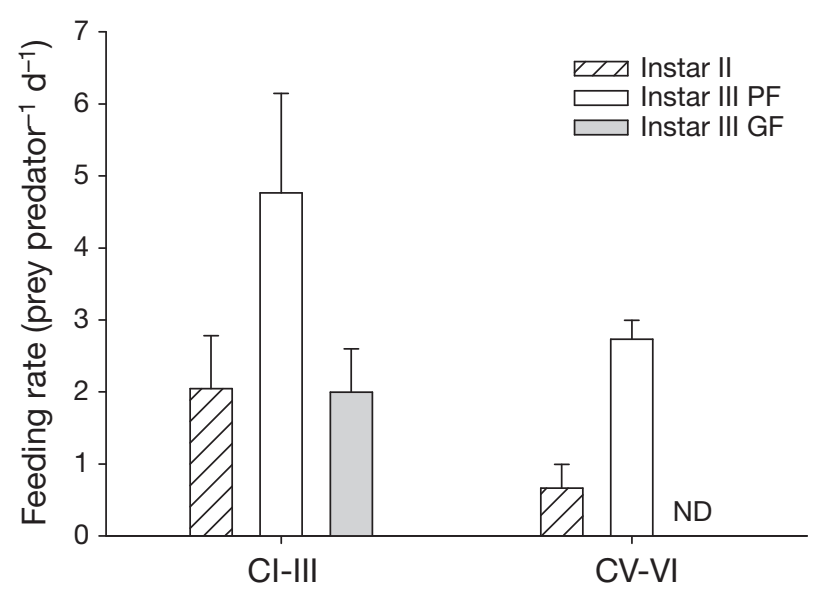

Fig. 1. Cercopagis pengoi and Eurytemora affinis. Feeding rate (mean $\pm \mathrm{SE}$ ) of different developmental stages of $C$. pengoi on E. affinis copepodites (CI-III) and adults (CV-VI) at concentrations of 100 prey $\mathrm{l}^{-1}$. ND: no data; PF: parthenogenic females; GF: gametogenic females 
$\mathrm{p}=0.26$ ), or between GF Instar III and Instar II individuals $(p=0.72)$. The feeding rates on copepodites and adults of $E$. affinis did not differ significantly (ANOVA: $F_{1,20}=2.08, \mathrm{p}=0.165$ ).

The prey density affected the FRs of Cercopagis pengoi (Fig. 2). Significantly more copepodites were eaten at 200 than at 100 ind. $\mathrm{l}^{-1}$ (ANOVA: $F_{1,14}=2.51$, $\mathrm{p}=0.0008$ ). There was no effect of $C$. pengoi developmental stage on the FR at different prey densities (ANOVA: $F_{1,14}=0.08, \mathrm{p}=0.778$ ), nor was the interaction between prey density and predator stage significant (ANOVA: $F_{1,14}=2.09, \mathrm{p}=0.170$ ).

\section{Variations in abundance}

Year-to-year variations in both Eurytemora affinis and Cercopagis pengoi abundances in the Gulf of Finland were considerable (Fig. 3). When the copepod abundances were examined for the whole water column, clear changes could be seen after the $C$. pengoi invasion: the abundances had decreased by $47 \%$ in the central and by $64 \%$ in the eastern Gulf, but increased by $56 \%$ in the west. In the period 1992 to 1996, E. affinis abundances in the mixing layer were high at 0 to $20 \mathrm{~m}$ (Fig. 3a,b,c); however, following the massappearance of $C$. pengoi in 1997, they declined significantly (Mann-Whitney $U$-test: $U=3.18, \mathrm{n}_{1}=14$, $\mathrm{n}_{2}=22, \mathrm{p}=0.0015$ ). Maximum densities of $E$. affinis (43500 ind. $\mathrm{m}^{-3}$ ) were observed in the eastern Gulf of Finland in 1993, with average abundances before the invasion of 5800 ind. $\mathrm{m}^{-3}$ (west), 18700 ind. $\mathrm{m}^{-3}$ (central), and 24600 ind. $\mathrm{m}^{-3}$ (east). After the invasion, the densities of $E$. affinis decreased by 37 to $85 \%$, averaging 3700 ind. $\mathrm{m}^{-3}$ (west), 5300 ind. $\mathrm{m}^{-3}$ (central), and

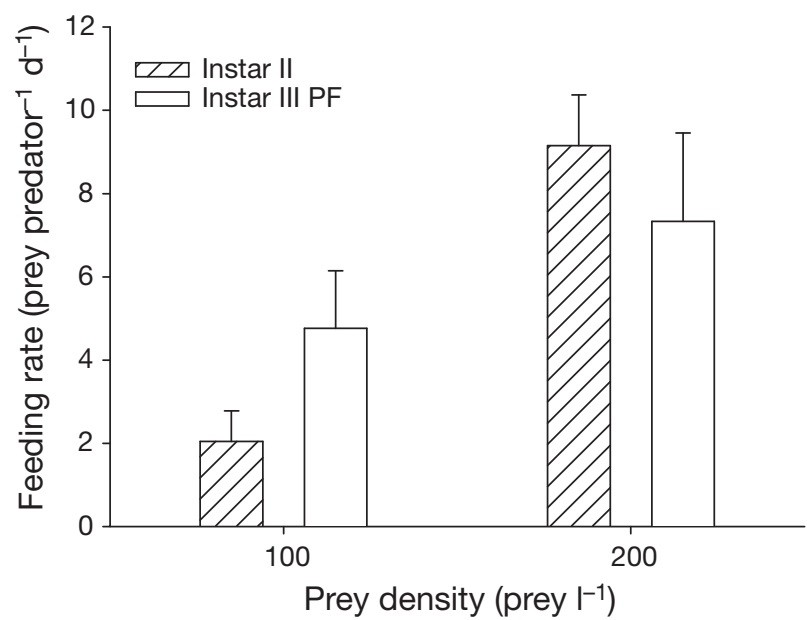

Fig. 2. Cercopagis pengoi and Eurytemora affinis. Feeding rate (mean $\pm \mathrm{SE}$ ) of instar II and III parthenogenic females (PF) of C. pengoi on E. affinis copepodites (CI-III) at 2 prey concentrations
3800 ind. $\mathrm{m}^{-3}$ (east). The most remarkable decline (by $85 \%$ ) in the copepod densities was observed in the eastern Gulf of Finland (Mann-Whitney $U$-test: $U=$ 2.35, $\mathrm{n}_{1}=5, \mathrm{n}_{2}=7, \mathrm{p}=0.019$ ), where $C$. pengoi was most abundant. The highest numbers of $C$. pengoi were recorded in 1997 and 2002, with 471 and 343 ind. $\mathrm{m}^{-3}$, respectively. In other parts of the Gulf, average abundances of $C$. pengoi over the years were generally lower, at 95 ind. $\mathrm{m}^{-3}$ in the central part and further decreasing to 51 ind. $\mathrm{m}^{-3}$ in the west. In these parts of the Gulf, the change in the E. affinis abundances was not significant (Mann-Whitney $U$-test: $\mathrm{p}=0.059, \mathrm{p}=$ 0.306, central and west, respectively).

Both Cercopagis pengoi and Eurytemora affinis were less abundant below the thermocline. On average, only 1 to $24 C$. pengoi ind. $\mathrm{m}^{-3}$ were observed (maximum abundance of 51 ind. $\mathrm{m}^{-3}$ in 1997 in the eastern Gulf). Average densities of $E$. affinis before the 1997 were 1500 ind. $\mathrm{m}^{-3}$ (west), 11100 (central), and 4800 (east), while after the C. pengoi invasion, they dropped by $51 \%$ in the central Gulf and by $23 \%$ in the east. However, the opposite was observed in the western Gulf, where E. affinis abundances below the thermocline increased by $83 \%$ (Fig. 3f). However, the change in the abundances below the thermocline was not significant in any parts of the Gulf due to high inter-annual variability (Mann-Whitney $U$-test: $\mathrm{p}>$ 0.05 for all areas).

\section{In situ predation rates}

To apply our experimental FRs to nature, we fitted linear regressions using FR (prey predator ${ }^{-1} \mathrm{~d}^{-1}$ ) as the dependent variable and prey density ( $\mathrm{PD}$, prey $\mathrm{m}^{-3}$ ) as the independent variable to derive predation rates corresponding to average natural prey densities. Linear regressions were forced through the origin since there is no feeding at zero prey densities. The regression equations ( $p<0.05$ in both cases) were:

$$
\begin{gathered}
\mathrm{FR}=0.389 \times 10^{-4} \times \mathrm{PD}, \mathrm{r}^{2}=0.97, \text { for Instar III } \mathrm{PF} \\
\mathrm{FR}=0.407 \times 10^{-4} \times \mathrm{PD}, \mathrm{r}^{2}=0.89, \text { for Instar II }
\end{gathered}
$$

FR of Instar III GF was assumed to follow the same linear regression as Instar II individuals, as their FR at the identical prey densities were very close (Fig. 1). Further, for calculating the in situ FR, we pooled all stages of copepods (CI-VI), because no significant differences were found between the FR on CI-III and CIV-VI (Fig. 1). FRs were calculated separately for instars III PF and GF as well as for Instar II Cercopagis pengoi based on their observed natural abundances (Fig. 3). Instar II FRs were estimated based on both Instar I and II natural abundances. 

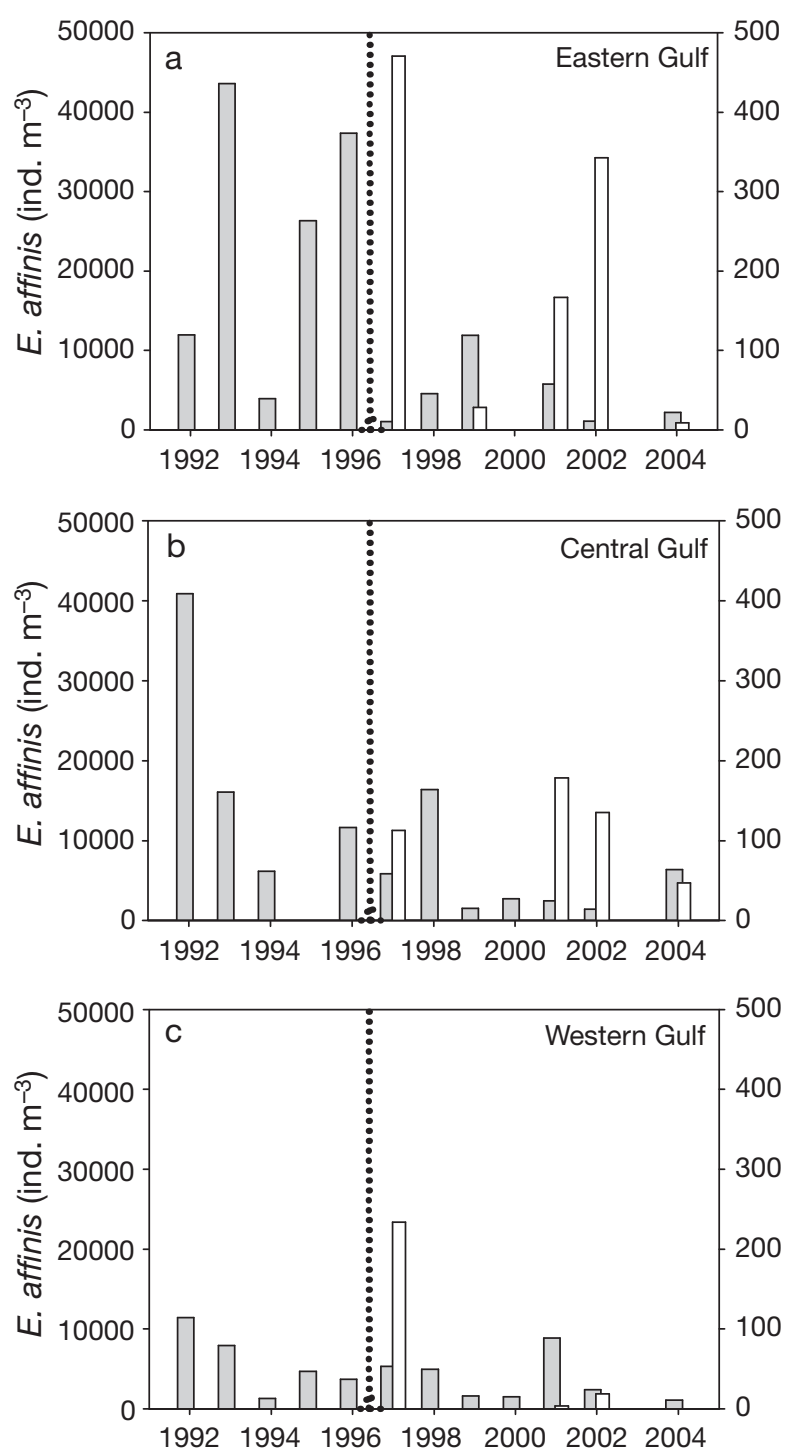
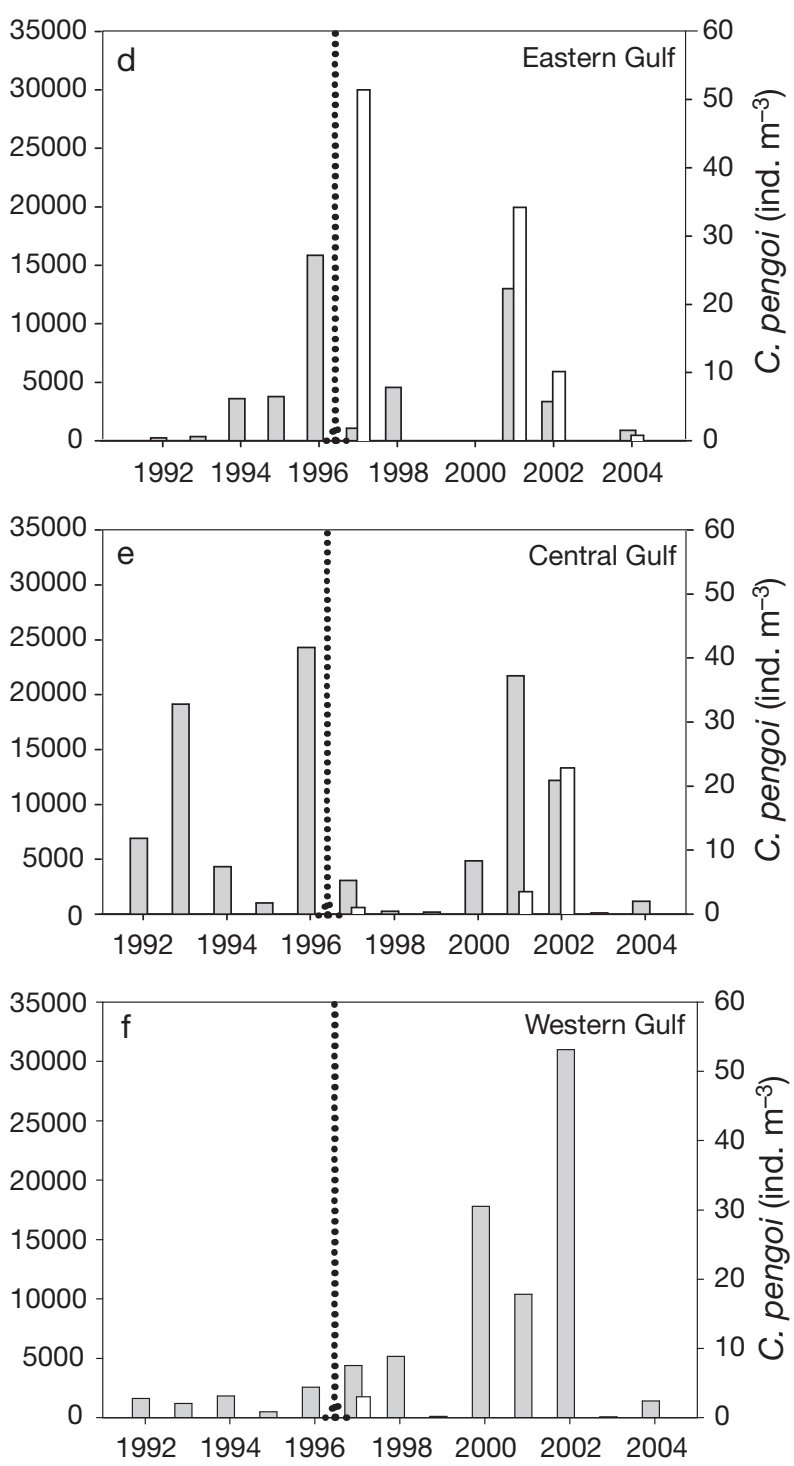

Fig. 3. Cercopagis pengoi and Eurytemora affinis. Annual August abundances of E. affinis (grey bars) and C. pengoi (white bars) in different parts of the Gulf of Finland, Baltic Sea, (a,b,c) above the thermocline (ca. 0 to $20 \mathrm{~m}$ ) and (d,e,f) below the thermocline (ca. 20 to $65 \mathrm{~m}$ ) before (1992 to 1996) and after (1997 to 2004) C. pengoi expansion (marked with a dotted line). Note the different $y$-axis scales in left and right panels

At maximum, the Cercopagis pengoi population could consume up to 105540 Eurytemora affinis $\mathrm{m}^{-3}$ daily, if the predator is as abundant as during the peak recorded in the eastern Gulf of Finland in 1997 (1800 ind. $\mathrm{m}^{-3}$; Uitto et al. 1999), occurs mostly above the thermocline, and feeds at rates derived for the assumed prey vertical distribution (Nikolaev 1960, Vuorinen 1987, Gorokhova 1999). However, C. pengoi rarely reaches such high abundances in the Baltic Sea, and its average numbers usually vary between 60 and 350 ind. $\mathrm{m}^{-3}$ (Ojaveer \& Lumberg 1995, Gorokhova et al. 2000, Ojaveer et al. 2004, this study). Daily predation rates calculated based on the average $C$. pengoi abundances are much lower, varying from 87 to 1961 E. affinis $\mathrm{m}^{-3}$ in the western, 331 to 6467 ind. $\mathrm{m}^{-3}$ in the central, and 23 to 3874 ind. $\mathrm{m}^{-3}$ in the eastern Gulf of Finland. The large variation in the predation rates is due to the high inter-annual variability of the abundance estimates of both prey and predator (Fig. 3).

\section{DISCUSSION}

The energy flow in the pelagic food webs and their structure are to a large extent determined by the food selectivity of pelagic predators. For invertebrate pre- 
dators, the most important factor in prey selection is often the capability of the predator to capture prey, and some prey types may be too large or have strong escape abilities (e.g. Browman et al. 1989, Viherluoto \& Viitasalo 2001). In general, it is assumed that predators capture smaller prey than themselves, and for raptorial zooplankton, the predator:prey size ratio is ca. 10:1 (see Hansen et al. 1994 for a review). Apparently, Cercopagis pengoi is an exception to this general rule, as it is able to capture and ingest prey that is about half of its own size, i.e. individuals of Instar II were observed to eat adults of the calanoid copepod Eurytemora affinis with a predator:prey size ratio as low as 2:1. The low predator-prey size ratios might be common for cercopagidids, as similarly low values have also been reported for Bythotrephes longimanus, another predatory cladoceran from the same family (Branstrator 2005), whereas this ratio for another raptorial cladoceran, Leptodora kindtii (Haplopoda), is closer to the general rule (Branstrator 2005). The FRs (prey predator $^{-1} \mathrm{~d}^{-1}$ ) of Bythotrephes spp. and L. kindtii on herbivorous cladocerans range from 10 to 14 (Browman et al. 1989) and are similar to those of $C$. pengoi feeding on small zooplankton (up to 16 for cladocerans and copepodites, and 22 to 27 for nauplii and rotifers; Laxson et al. 2003, Lehtiniemi \& Lindén 2006, Simm et al. 2006). Our results are the first to demonstrate the ability of C. pengoi to capture and ingest large and motile prey, such as adult calanoid copepods, indicating that this non-indigenous cladoceran may influence native prey populations on a wider scale than previously anticipated. The FRs observed are similar to those reported for $C$. pengoi feeding on cladocerans (3 prey predator $^{-1}$ $\mathrm{d}^{-1}$, Laxson et al. 2003), despite the fact that copepods are much better at escaping predators (Viitasalo et al. 2001). It is likely that C. pengoi also feeds on the other common Baltic copepods, Acartia spp., which have a weaker escape response compared to E. affinis (Viitasalo et al. 2001).

Our results indicate that a dense Cercopagis pengoi population has a potential to exert a substantial predation pressure on native copepods, as we observed a remarkable $85 \%$ post-invasion decline in Eurytemora affinis stocks in the eastern parts of the Gulf, where C. pengoi was most abundant. This lends strong support to the observed seasonal population increase of $C$. pengoi that closely follows that of E. affinis in the Gulf of Riga (Ojaveer et al. 2004), suggesting a bottomup control for C. pengoi abundance. This is also in agreement with seasonal time series from Lake Ontario that showed decreased copepodite abundances after the C. pengoi invasion (Benoît et al. 2002). Other factors might be involved as well in the observed copepod dynamics; however, their contribution remains to be evaluated. In particular, both C. pengoi and E. affi- nis prefer similar hydrographical conditions, viz. warm water and a stable water column (Viitasalo et al. 1995, Ojaveer et al. 2004), which suggests that their peak abundances should occur in concert; however, this was not the case (Fig 3). During 1992 to 2004 in the eastern Gulf, temperature and salinity fluctuated (surface temperature: 16 to $21^{\circ} \mathrm{C}$, salinity: 4.3 to $4.6 \mathrm{PSU}_{\text {; FIMR }}$ monitoring data for August); however, no clear trends that could explain the decline in the copepod abundance were observed. Changes in fish predation might also have had an effect on the copepod, because the stock sizes of the dominating planktivorous fishes, herring and sprat, changed during the study period. In the Baltic, while herring stocks have decreased, sprat has increased in abundance (ICES 2006). Therefore, the overall change in the predation pressure on the copepods is not likely to be appreciable, as diets of both fish species largely overlap (Peltonen et al. 2004). However, the sizes of these major planktivorous fish stocks are not separately assessed for the Gulf of Finland; this causes additional uncertainty. In the eastern part of the Gulf, clupeoids feed preferentially on cladocerans, whereas in the western part of the Gulf, they select E. affinis over other prey (Peltonen et al. 2004). Thus, changes in the predation pressure should have resulted in stronger effects on the E. affinis population in the west compared to the eastern parts, which was not the case (Fig. 3). On the other hand, this prey selectivity may explain the larger proportion of copepods in the deeper waters in the west (Fig. 3).

Our estimates of the Cercopagis pengoi population predation rates on Eurytemora affinis are most realistic when copepod abundances are similar to the experimental densities, which can occur in the Baltic Sea due to uneven distribution of copepods and their aggregations at the top of the thermocline (Nikolaev 1960, Vuorinen 1987, Gorokhova 1999). However, the regression for the FRs is based on only 2 experimental prey densities, which may affect the reliability of the predation estimates at low prey abundances by underestimating the FRs due to the assumed linear fit. Another source of error is the inadequate abundance assessment of $C$. pengoi due to its patchiness and poor sampling coverage (note that samples were taken only in August), which may affect the in situ population predation rate estimates. Sampling was conducted during the time of the peak abundances of both zooplankton species, which usually occurs from late July to early September (C. pengoi: Gorokhova et al. 2000, Ojaveer et al. 2004; E. affinis: Viitasalo et al. 1995). The abundances of both C. pengoi and E. affinis in August varied greatly between different parts of the Gulf of Finland, with a pronounced east-west gradient and much higher values at the easternmost stations as also observed by Uitto et al. (1999). The trend is in fact gen- 
eral for zooplankton biomass distribution in the Gulf (Telesh 2004), suggesting that both species maintain residency in the proximal part of the estuary. Several mechanisms could be responsible for this, including low salinity water ( 3 to 4 PSU) and low rate of water exchange (Pitkänen et al. 1993), elevated concentrations of food available due to higher nutrient loading (Telesh 2004), and reproduction mode of these zooplankters, which is favored in estuarine shallow water conditions (both species carry their eggs/embryos until the release, and produce resting eggs). In the water column, C. pengoi is most abundant above the thermocline, although it also occurs in deeper waters (this study), while in E. affinis, the major part of the population is confined to the thermocline during daytime and migrates upwards to the surface at night (Vuorinen 1987). Thus, C. pengoi and E. affinis have largely overlapping horizontal and vertical distributions. Interestingly, the vertical distribution of the E. affinis population has changed dramatically after the appearance of C. pengoi in the western Gulf of Finland, with the major part of the population residing now below the thermocline. This was not apparent at the east and midbay stations where copepod abundances decreased throughout the water column (Fig. 3). Vuorinen (1987) estimated that in E. affinis populations in the Archipelago Sea (northern Baltic), vertical migration below the thermocline is advantageous when daily mortality of females caused by predation in the surface layer exceeds $7.5 \%$. Thus, if cumulative predation on E. affinis reaches the threshold due to the extensive fish predation and the additional predation exerted by C. pengoi, it forces the copepod population to migrate deeper in the water column and stay there during light hours to avoid visual predators. The induced migrations may imply severe costs for E. affinis, e.g. longer generation development times due to low temperature, decreased fecundity due to increased losses from migration, and poor food (Vuorinen 1987), which might be detrimental for population growth.

\section{Ecosystem consequences}

Eurytemora affinis is 1 of the few dominant mesozooplankton species in the northern Baltic Sea and is a major food source for planktivorous fishes and mysids (Flinkman et al. 1998, Viherluoto et al. 2000). A decrease in the mean weight-at-age was first observed in Baltic herring, and, since 1994, in sprat, indicating a limitation in food quality (Flinkman et al. 1998, Kornilovs et al. 2001). Since the 1980s, salinity has decreased in the northern Baltic Sea, resulting in a decreased abundance of the favored prey species, the marine copepod Pseudocalanus acuspes. Thus, the predation pressure on the remaining mesozooplankton community has increased. We propose that Cercopagis pengoi enhances predation pressure and competition for food among zooplanktivores in the eastern part of the Gulf of Finland, whereas in the western part, fish are the major zooplankton predators.

Under optimal conditions, Cercopagis pengoi reproduces parthenogenically and rapidly reaches high population densities (Simm \& Ojaveer 2006), affecting prey populations and higher trophic levels exploiting the same food resources. Although the direct effects on the prey populations could be observed during only a few months (July to September; Benoît et al. 2002, Ojaveer et al. 2004), the indirect effects (i.e. decreased growth rates, altered demographic structure, and seasonal development; Ojaveer et al. 2004) might cause a collapse in exploited prey communities (Kerfoot \& Sih 1987). Our results show that C. pengoi imposes predation pressure on large copepods, not only on smaller prey as previously thought (Laxson et al. 2003, Ojaveer et al. 2004, Lehtiniemi \& Lindén 2006, Simm et al. 2006). This should be taken into account in assessments of pelagic energy flows and zooplanktivory in the invaded ecosystems. Given the current situation with fisheries in the Baltic (ICES 2006) as well as the Great Lakes (Mills et al. 2005), this is of a particular concern for the assessment of fish predation effects on zooplankton as well as effects of zooplankton availability on fish recruitment.

Acknowledgements. We thank FIMR for the facilities on board RV 'Aranda' and for the zooplankton abundance data, the crew of RV 'Aranda' for help in plankton sampling, and E. Lindén and several anonymous referees for comments on earlier versions of the manuscript. The study was financed by The Academy of Finland (project \#203799, M.L.) and The Swedish Environmental Protection Agency (AquAliens program, E.G.).

\section{LITERATURE CITED}

Benoît HP, Johannsson OE, Warner DM, Sprules WG, Rudstam LG (2002) Assessing the impact of a recent predatory invader: the population dynamics, vertical distribution, and potential prey of Cercopagis pengoi in Lake Ontario. Limnol Oceanogr 47:626-635

Branstrator D (2005) Contrasting life histories of the predatory cladocerans Leptodora kindtii and Bythotrephes longimanus. J Plankton Res 27:569-585

Browman HI, Kruse S, O'Brien WJ (1989) Foraging behavior of the predaceous cladoceran, Leptodora kindtii, and escape responses of their prey. J Plankton Res 11:1075-1088

Flinkman J, Aro E, Vuorinen I, Viitasalo M (1998) Changes in northern Baltic zooplankton and herring nutrition from 1980s to 1990s: top-down and bottom-up processes at work. Mar Ecol Prog Ser 165:127-136

Gorokhova E (1999) Vertical structures in the Baltic pelagic ecosystem. Proc 3rd BASYS Annu Sci Conf, SP2-5, Paper Abstracts: 20 
Gorokhova E, Hansson S (2000) Elemental composition of Mysis mixta (Crustacea, Mysidacea) and energy costs of reproduction and embryogenesis under laboratory conditions. J Exp Mar Biol Ecol 246:103-123

Gorokhova E, Lehtiniemi M (2007) A combined approach to understand trophic interactions between Cercopagis pengoi (Cladocera: Onychopoda) and mysids in the Gulf of Finland. Limnol Oceanogr 52:685-695

Gorokhova E, Aladin N, Dumont HJ (2000) Further expansion of the genus Cercopagis (Crustacea, Branchiopoda, Onychopoda) in the Baltic Sea, with notes on the taxa present and their ecology. Hydrobiologia 429:207-218

Gorokhova E, Hansson S, Höglander H, Andersen CM (2005) Stable isotopes show food web changes after invasion by the predatory cladoceran Cercopagis pengoi in a Baltic Sea bay. Oecologia 143:251-259

Hansen B, Bjørnsen PK, Hansen PJ (1994) The size ratio between planktonic predators and their prey. Limnol Oceanogr 39:395-403

ICES (International Council for the Exploration of the Sea) (2006) Report of the ICES Advisory Committee on Fishery Management, Advisory Committee on the Marine Environment and Advisory Committee on Ecosystems, 2006. ICES Advice, Book 8. ICES, Copenhagen

Kerfoot WC, Sih A (1987) Predation: direct and indirect impacts on aquatic communities. University Press of New England, Hanover, NH

Kornilovs G, Sidrevics L, Dippner JW (2001) Fish and zooplankton interactions in the central Baltic Sea. ICES J Mar Sci 58:579-588

Laxson CL, McPhedran KN, Makarewicz JC, Telesh IV, MacIsaac HJ (2003) Effects of the non-indigenous cladoceran Cercopagis pengoi on the lower food web of Lake Ontario. Freshw Biol 48:2094-2106

Lehtiniemi M, Lindén E (2006) Cercopagis pengoi and Mysis spp. alter their feeding rate and prey selection under predation risk of herring (Clupea harengus membras). Mar Biol 149:845-854

Litvinchuk LF, Telesh IV (2006) Distribution, population structure and ecosystem effects of the invader Cercopagis pengoi (Polyphemoidea, Cladocera) in the Gulf of Finland and the open Baltic Sea. Oceanologia 48:243-257

Mills EL, Casselman JM, Dermott R, Fitzsimons JD and others (2005) A synthesis of ecological and fish community changes in Lake Ontario, 1970-2000. Great Lakes Fish Comm Tech Rep 67

Nikolaev II (1960) Daily vertical migrations of some crustaceans in the Baltic Sea. Tr Vses Nauchno-issled Inst Morsk Rybn Khoz Okeanogr 42:61-74. English Translation of Fisheries and Aquatic Sciences, No. 5317, Canada Institute for Scientific and Technical Information, Ottawa, 1987

Ojaveer H, Lumberg A (1995) On the role of Cercopagis (Cercopagis) pengoi (Ostroumov) in Pärnu Bay and the NE part of the Gulf of Riga ecosystem. Proc Est Acad Sci Ecol 5:20-25

Ojaveer H, Simm H, Lankov I (2004) Population dynamics and

Editorial responsibility: Matthias Seaman,

Oldendorf/Luhe, Germany ecological impact of the non-indigenous Cercopagis pengoi in the Gulf of Riga (Baltic Sea). Hydrobiologia 522: 261-269

> Peltonen H, Vinni M, Lappalainen A, Pönni J (2004) Spatial distribution patterns of herring (Clupea harengus L.), sprat (Sprattus sprattus L.) and the three-spined stickleback (Gasterosteus aculeatus L.) in the Gulf of Finland, Baltic Sea. ICES J Mar Sci 61:966-971

Pitkänen H, Tamminen T, Kangas P, Huttula T and others (1993) Late summer trophic conditions in the north-east Gulf of Finland and the river Neva estuary, Baltic Sea. Estuar Coast Shelf Sci 37:453-474

Simm M, Ojaveer H (2006) Taxonomic status and reproduction dynamics of the non-indigenous Cercopagis in the Gulf of Riga (Baltic Sea). Hydrobiologia 554:147-154

Simm M, Lankov A, Põllupüü M, Ojaveer H (2006) Estimation of consumption rates of the predatory cladoceran Cercopagis pengoi in laboratory conditions. Est Mar Inst Rep Ser 14:42-47

Telesh IV (2004) Plankton of the Baltic estuarine ecosystems with emphasis on Neva Estuary: a review of present knowledge and research perspectives. Mar Pollut Bull 49:206-219

Uitto A, Gorokhova E, Välipakka P (1999) Distribution of the non-indigenous Cercopagis pengoi in the coastal waters of the eastern Gulf of Finland. ICES J Mar Sci 56:49-57

> Vanderploeg HA, Nalepa TF, Jude DJ, Mills EL and others (2002) Dispersal and emerging ecological impacts of Ponto-Caspian species in the Laurentian Great Lakes. Can J Fish Aquat Sci 59:1209-1228

Viherluoto M, Viitasalo M (2001) Temporal variability in functional responses and prey selectivity of the pelagic mysid, Mysis mixta, in natural prey assemblages. Mar Biol 138:575-583

Viherluoto M, Kuosa H, Flinkman J, Viitasalo M (2000) Food utilisation of pelagic mysids, Mysis mixta and M. relicta, during their growing season in the northern Baltic Sea. Mar Biol 136:553-559

Viitasalo M (1992) Mesozooplankton of the Gulf of Finland and northern Baltic Proper - a review of monitoring data. Ophelia 35:147-168

Viitasalo M, Vuorinen I, Saesmaa S (1995) Mesozooplankton dynamics in the northern Baltic Sea: implications of variations in hydrography and climate. J Plankton Res 17: $1857-1878$

> Viitasalo M, Flinkman J, Viherluoto M (2001) Zooplanktivory in the Baltic Sea: a comparison of prey selectivity by Clupea harengus and Mysis mixta, with reference to prey escape reactions. Mar Ecol Prog Ser 216:191-200

> Vuorinen I (1987) Vertical migration of Eurytemora (Crustacea, Copepoda): a compromise between the risks of predation and decreased fecundity. J Plankton Res 9: $1037-1046$

Witt AM, Dettmers JM, Cáceres CE (2005) Cercopagis pengoi in southwestern Lake Michigan in the four years following invasion. J Great Lakes Res 31:245-252

Submitted: July 2, 2007; Accepted: February 4, 2008

Proofs received from author(s): June 13, 2008 